\title{
IoT Based Flow Valve Control and Accounting System
}

\author{
Vijaykumar M, Vishnu Shivalingappa Toragall, Gagana P Rao, Kavya G V, Vinutha D C
}

\begin{abstract}
The most important and necessary factor for all living individuals in the present world is water. Drinking water utilization suffers from many problems or difficulties in real-time execution. Nowadays, due to increasing population providing drinking water facilities to everywhere is a big challenge resulted in insufficiency of water. Water contamination is the main cause for scarcity of water. The main reasons for water pollution are use of pesticides, chemical fertilizers and Industrialization. Due to this, Water gets contaminated and it causes severe problems like waterborne infections to individual lives and it also hazardous to aquatic life. Due to all this there is need for water quality checking in specific duration of time or regularly. Parameters that are to be checked to assess the water quality are Temperature, $\mathrm{pH}$, turbidity and Salinity. Based on the measurement obtained about the parameter the water usage will be decided.
\end{abstract}

\section{Keywords: Temperature, PH, Turbidity, Salinity}

\section{INTRODUCTION}

Drinking water supply undergoes many problems in current generation. The challenge occurs due to inadequate water supplies and growth in population. So there is a necessity for water quality monitoring. Normal or traditional methods of water quality checking require regular collecting water from the resources and supported through laboratory analytic techniques to check this quality of water. These techniques take longer duration and it is not an efficient way of water quality checking. Since there exists some requirements towards constant online water quality monitoring. Over concentrating on the earlier problems our article helps to improve low-cost method to real-time monitoring from this stream property toward the Internet of Things (IoT) environment. This design method uses a specific IOT module to obtaining sensor data of the core controller to the cloud and these values of the sensor information can be recognized at this cloud applying a specific IP address. According to some values of these sensors, the drinking water and the livestock purposes water is separated. The bills are generated by the water department

\section{Revised Manuscript Received on December 14, 2019}

Vijaykumar M, Dept. of ISE, Vidyavardhaka College of Engineering, Mysuru, Visvesvaraya Technological University, Belagavi, Karnataka. Email: vijaykumarm7026@gmail.com

Vishnu Shivalingappa Toragall, Dept. of ISE, Vidyavardhaka College of Engineering, Mysuru, Visvesvaraya Technological University, Belagavi, Karnataka.Email: vishnutoragal2@gmail.com

Gagana P Rao, Dept. of ISE, Vidyavardhaka College of Engineering, Mysuru, Visvesvaraya Technological University, Belagavi, Karnataka. Email: Gaganarao1597@gmail.com

Kavya G V, Dept. of ISE, Vidyavardhaka College of Engineering, Mysuru, Visvesvaraya Technological University, Belagavi, Karnataka. Email: kavyagv67@gmail.com

Vinutha D C Dept. of ISE, Vidyavardhaka College of Engineering, Mysuru, Visvesvaraya Technological University, Belagavi, Karnataka. Email:Vinuthadc@vvce.ac.in

based on the unit of water used. Additionally, this IoT module further implements $\mathrm{Wi}-\mathrm{Fi}$ for observing the statistics on mobile. Figure 1 shows the water accessibility in per capita in India.

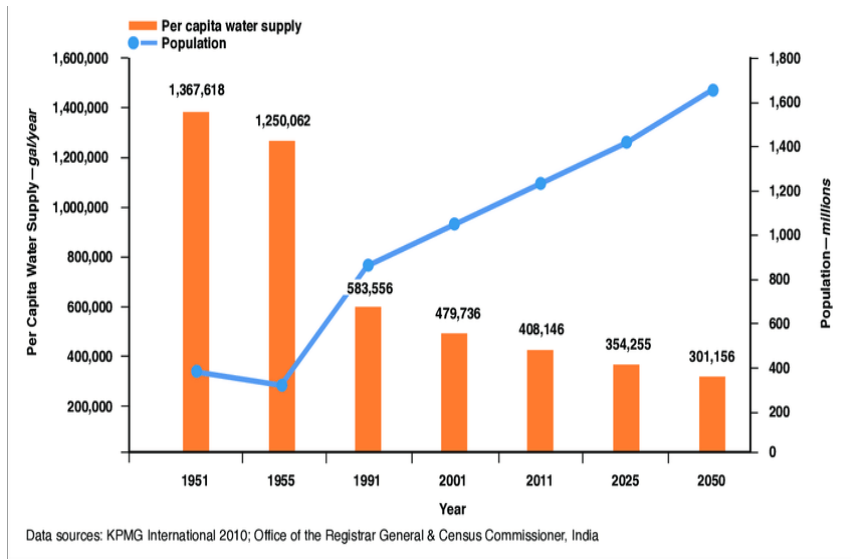

Figure.1. water accessibility in per capita in India.

\section{RELATED WORK}

In [1], From the prospect of data acquiring, synchromesh and analysis reason there are three subsystems for water quality monitoring, data accumulation, transmission and analysis .Data collection system gives the information about the parameter of water used for water monitoring, The analysis system gives the measurement of parameters and from transmission system, data transfer and management is done. Based on the measurement, decision will be taken whether to use that particular water for drinking purpose or livestock purpose. In [2], the chemical, biological and physical factors describe the quality of water. Use of pesticides, chemical fertilizer and industrialization is deteriorating the water quality. Water borne disease will be caused by using contamination water in day today living purpose. So the assessment of water is necessary nowadays. WQI (Water Quality Index) shows the state of water, based on that value water is used. In [3], water quality depends on many factors like $\mathrm{pH}$, salinity, Temperature, Turbidity etc. for drinking water there is some threshold measurement for these factors. If the measurement crosses the threshold value then that water is not portable for drinking and it should be used for other purpose. The measurement of factors done using sensors based on the values from the sensors, the quality of water is decided. 


\section{IoT Based Flow Valve Control and Accounting System}

In [4], Due to the rise in society and insufficient water supplies, water scarcity is taken place. So there is need for perfect utilization of water. Using Remote Sensing and Internet of Things (IoT) Technique, the water quality data is collected and analysis will be done. Based on the data water is used. If the water quality is not good then these may cause disease to the people who are using it. So there is need for regularly monitoring the quality of water, by collecting samples and testing the quality using IoT and Remote Sensing Technique. Using GSM technology information will be send to the user to take the appropriate action based on the quality of water. In [5], water is the various essential elements for every living being. There are many water purification methods are available but still there is no regular monitoring of drinking water. So this should automated using available technologies like Internet of Things (IoT), Cloud, Raspberry-pi Sensors and module. The product of the analysis is fed into the cloud. Of cloud that information will be monitored by the Water Monitoring Board (WMT) to find whether water can be used for drinking purpose or not and data examined will be uploaded to public domain for public reference. In [6], in many parts of the world the main reason for disease causing is water pollution water pollution , and theft of water using temperature sensor $\mathrm{pH}$ sensor flow sensor .All these sensors are coordinate integrated in Arduino board using GSM component these system can be well tuned and it will be cost efficient and can be implemented by anyone. In [7], it notifies the real-time parameter of water on using certain physical and chemical factors of water quality such as temperature, $\mathrm{pH}$, conductivity, movement and rusting-decrease potential. The physical and chemical parameter is used whether the water is polluted or contaminated. The sensors are combined with the micro-controller based scaling node also analyze this data. $\mathrm{Zig}$ Bee receiver has used the communication between the nodes it gives the audio alerts and visual representation when the water quality is varied. In [8] The water pollution can be strongly done under the lab but the aim is to find the pollution in real-time through implementing the multiple sensors to the source we need to monitor it represents the result of dissolved oxygen, PHP level, temperature, and turbidity, In [9] This paper illustrates the smart cost multisensory method to the water quality monitoring the implementation of water framework directive over EU and the global accent increase towards the administration of the water quality continues growing to expand the weather for the novels minimization and the smart monitoring operations for freshwater attachments transitional and costal water some of the parameters used in this system are: conductivity, $\mathrm{pH}$, turbidity, dissolved oxygen, temperature phosphate and stream level. In [10] That method is used to regulate the sense of water which relates diff sensors like $\mathrm{pH}$, temperature and liquefied oxygen level unit the data which are collected from this system are calculated randomly and is stored in database on water as quality for further analyze of the quality checking this completes the relationship among the sensors like $\mathrm{pH}$, temperature and oxygen level is analyzed this briefly summaries that this $\mathrm{pH}$ and level of dissolved is directly proportional to temperature. Integrated in Arduino board using GSM component these system can be well tuned and it will be cost efficient and can be implemented by anyone.

\section{RESULTS AND DISCUSSIONS}

This IoT model is used for real time water quality checking using sensors like temperature sensor, $\mathrm{pH}$ sensor, salinity sensor, turbidity sensors. Based on the measurement obtained from these sensors is used to separate the water into two separate chambers based on the water quality. Firstly there is threshold measurement is set for every parameter, if the measurement is doesn't fall under the threshold value then that water cannot be used for drinking purpose. A threshold value for the parameter varies from season to season for some particular of time. The main objective is to provide pure drinking water of people. One chamber is used for drinking water and the other one for cleaning or livestock purposes. It also extends the feature to identify the water flow and the system will calculate the water bill based on the consumption flow in each chamber using the flow sensor. Embedded ' $\mathrm{C}$ ' is used to read analog data, in this module we develop an embedded "c" code to communicate with sensors using various technical parameters like baud rate, start bit, stop bit, Serial object communication. Data Acquisition Module is used once the device is in the water pipeline, we need to start communicating with the device using asynchronous coding and capture live data from the connected sensors and threshold matching algorithms. Once we get the data from the sensors, it's necessary to match with the master data set using Machine learning supervised system to find a match towards water quality identification. Sending the data to the cloud using the Message Queuing telemetry Transport (MQTT) protocol. In order to send readings, we should implement an MQTT server which is capable of starting services and enable sender and receiver to communicate. Receiving the end MQTT subscriber module uses Communication protocol using lightweight data exchange between IoT model and server, Desktop application to manage customer profile. Module created using C\# language, Windows User interface to maintain customer profile, generating the bill and also alerting the user, Dashboard where the user can view complete consumption and also information about the live information collected via MQTT server, which will be running in EC2 cloud server (Linux server at Amazon service) Billing generation and alerting system. This module will be created to generate PDF and attach the same to the user email to identify consumption and for communication between Arduino and ESP8266 Wi-Fi module. In this module, we will be developing a serial program to collect data from Arduino and establish Wi-Fi hotspot application to connect to avail internet to post IoT data to cloud via MQTT service.

\section{SENSORS}




\section{A. Temperature in Water Quality Monitoring}

The temperature is a most important water property and environmental parameter. It decides the types of marine life in the water. It is capable of measuring the temperature between -5 to +50 degree. Figure 2 shows the Temperature sensor.

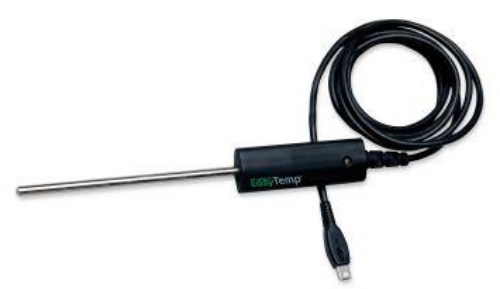

Figure 2. Temperature Sensor

\section{B. Salinity in Water Quality Monitoring}

Salinity is a representation of the amount of salt present in earth or water. This can be carried with a water exchange in facade and groundwater where salts are remarkably water-soluble. This uniform combination of the salt prospect is mentioned as primary salinity. Huge salt sediment deposits under soil facade, salt stores, and salt lakes. In regular situations, the thick roots of domestic plants consume the largest water filtering of the soil before it carries the salt combined in groundwater under the plant root area. Though, irrigation, reduced farm usage, wide herbage expulsion and industrial works have made it more adequate for salt to be dispatched to the soil exterior or waterways. The additional salt from these fitted property use and control methods are assigned to as 'unimportant salinity'. Turbidity in Water Quality Monitoring: It is the measure of murkiness in the water. That can differ from a stream with dirty soil and deposit anywhere it would be reduced to see into the high turbidity(water) to pure water which looks to be low turbidity(clear). Turbidity can be caused by Slit, Sand, and others, Biochemical precipitates, Bacteria's, and other germs. Figure 3 shows the Salinity sensor.

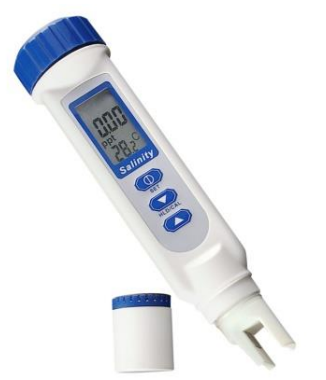

Figure 3.Salinity Sensor

\section{C. pH in Water Quality Monitoring}

$\mathrm{pH}$ is a measure of acidity from 0 - 14. It indicates whereby it is acidic or chemical substance. Likewise, acidic solvents produce a lower $\mathrm{pH}$. Also, alkali solvents produce a considerable more $\mathrm{pH}$. The physical matter that aren't acidic or stable (i.e., neutral solutions) normally have a $\mathrm{pH}$ of 7 . The $\mathrm{pH}$ of pure water is 7 . In general, water with a $\mathrm{pH}>7$ is estimated fundamental and a $\mathrm{pH}<7$ is estimated acidic. The average scale for the $\mathrm{pH}$ range in groundwater systems is

between $6-8.5$, and the $\mathrm{pH}$ in exterior waterways is $6.5-8.5$. Figure 4, shows the $\mathrm{pH}$ sensor.

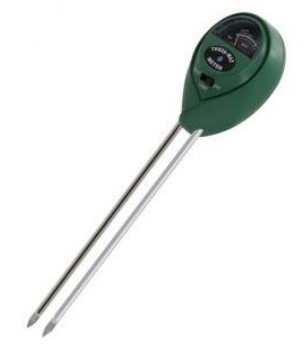

Figure 4.pH Sensor

\section{Water Flow Sensor :}

It consists of a versatile valve body and a magnetic-field detection sensor water rotor. When water enters into the rotor, It's velocity varies with several volumes of the flow and the rotor begins to roll. This hall- effect sensor outputs the like pulse Signal. Figure 5 shows the water flow sensor.

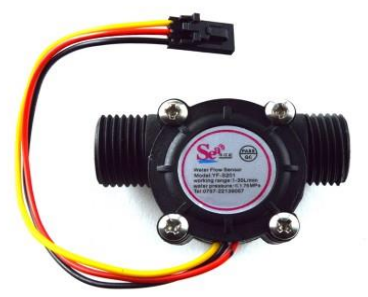

Figure 5.Water FlowSensor.

\section{CONCLUSION}

The proposed model is an automatic system monitor and controls the exact water requirements in domain .The intelligent system ensures wise use water. The system gives the correct measurement of drinking water. This increases the better utilization of available water. It decreases the disease caused through water or water borne disease. The system proposes a quick solution to the water monitoring or real time checking. The use of water was an important issue in development Countries like India .So the proposed system can help to reduce the water wastage and increases the effective utilization.

\section{REFERENCES}

1. Jianhua Dong Guoyin, Wang Huyong YanJi, Xuerui Zhang, “A of smart water quality monitoring system", 2015.

2. S. P. Gorde, M. V. Jadhav" Assessment of Water Quality Parameters: A Review" ISSN : 2248-9622, Vol. 3, Issue 6, Nov-Dec 2013 pp.2029-2035.

3. Gitelson,G. Garbuzov,F. Szilagyi,K-H. Mittenzwey,A. Karnieli,A. Kaiser, "Quantitative remote sensing methods for real-time monitoring of inland waters quality", 2007.

4. A. N. Prasad , K. A. Mamun ,F. R. Islam ,H. Haqva, "Smart water quality monitoring system", 2nd Asia-Pacific World Congress on Computer Science and Engineering (APWC on CSE),2015..

5. Pavana N R,Dr. M. C. Padma, "Design of Low Cost System for Real Time Monitoring of Water 


\section{IoT Based Flow Valve Control and Accounting System}

Quality Parameters in IOT Environment" May 2016,ISSN: 2321-7782 .

6. K.SaravananE. AnusuyaRaghvendraKumarLe Hoang Son "Real-time water quality monitoring using Internet of Things in SCADA" 29 August 2018.

7. Niel AndreCloete ,Reza Malekian , Lakshmi Nair“Design of Smart Sensors for Real-Time Water Quality Monitoring",2016.

8. Fiona Regan, AntoinLawlor ,Brendan O Flynn , J. Torres , R Martinez-Catala, C. O'Mathuna, John Wallace" A demonstration of wireless sensing for long term monitoring of water quality",2009 IEEE 34th Conference on Local Computer Networks.

9. B O'Flynn, Rafael Martinez-Catala, S. Harte, C. O'Mathuna , John Cleary,

C. Slater, F. Regan, "SmartCoast: A Wireless Sensor Network for Water Quality Monitoring", 32nd IEEE Conference on Local Computer Networks, 2007.

10. Alif Akbar Pranata, Jae Min Lee, Dong Seong Kim, "Towards an IoT-based water quality monitoring system with brokerless pub/sub architecture", 2017 IEEE International Symposium on Local and Metropolitan Area Networks.

\section{AUTHORS PROFILE}

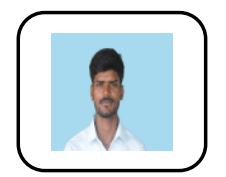

Vijay Kumar M Department of Information Science and Engineering, Vidyavardhaka College of Engineering.

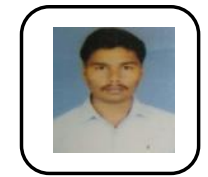

Vishnu Shivalingappa Toragall Department of Information Science and Engineering, Vidyavardhaka College of Engineering, Karnataka, India

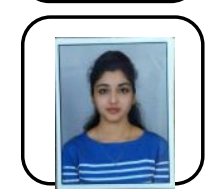

Gagana P Rao, Department of Information Science and Engineering, Vidyavardhaka College of Engineering, Karnataka, India

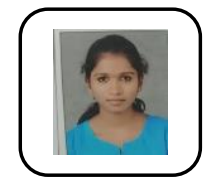

Kavya GV, Department of Information Science and Engineering, Vidyavardhaka College of Engineering, Karnataka, India

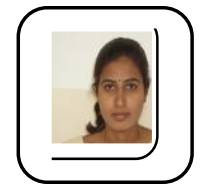

Mrs. Vinutha D C,Associate Professor, Department of Information Science and Engineering, Vidyavardhaka College of Engineering, Karnataka, India. Her research interests include Big Data Systems, Hadoop, Parallel Processing mechanisms, Scheduling. She has published more than 14 research papers. 